\title{
Inhaltsverzeichnis des ersten Bandes.
}

Vorwort $\ldots \ldots \ldots \ldots \ldots \ldots \ldots \ldots \ldots \ldots \ldots \ldots \ldots \ldots$, VII-XXV. XX

Erster Teil: Die Grundlagen des Reiches $\ldots \ldots \ldots \ldots \ldots \ldots \ldots, \quad \mathbf{1}-\mathbf{9 3}$

Erstes Kapitel: Das Land $\ldots \ldots \ldots \ldots \ldots \ldots \ldots \ldots, \quad \mathbf{1}-\mathbf{3 1}$

Zweites Kapitel: Das Volk $\ldots \ldots \ldots \ldots \ldots \ldots \ldots \ldots \ldots .32-60$

Drittes Kapitel: Die Urzeit. Entstehung des Staates. Der

Staatsgedanke $\ldots \ldots \ldots \ldots \ldots \ldots \ldots \ldots \ldots \ldots \ldots, 61-93$

Zweiter Teil: Der universalistische Staat des Altertums ....... 94-222

Erstes Kapitel: Quellen. Chronologie. Gründung der TschouDynastie. Gedanke und Idealform des Universalismus ... 94-132

Zweites Kapitel: Entwicklung, Verfall und Endedes Tschou-

Reiches ............................ 133-222

a) Die frühere Tschou-Zeit. Entstehung der Lehenstaaten $133-150$

b) Verfall der Zentralmacht. Erstarkung der Einzelstaaten. Die Tsch'un-ts'iu-Periode............ 150-178

c) Das Ende. Die Zeit der „Kampf-Staaten“ ....... 178-199

d) Das Geistesleben. Die Krisis im Staatsgedanken .... 199-222

Dritter Teil: Das Werden der neuen Form. Die Bildung des Einheitstaates und ihre Hemmungen $. \ldots \ldots \ldots \ldots \ldots \ldots \ldots .223-431$

Erstes Kapitel: Der neue Staat der Ts'in und sein Ende ... 223-267

Zweites Kapitel: Entstehung des Han-Reiches. Das Werden des konfuzianischen Staates ................. 268-320

a) Neubildung und Ende des Lehenswesens. Der Aufstieg des Konfuzianertums ................ 269-295

b) Die Konfuzianisierung des Staates.......... 295-320

Drittes Kapitel: Auswärtige Politik. Vorstöße nach allen Richtungen. Hunnenkriege. Neue Welten .......... 321-357

Viertes Kapitel: Der Staat, seine Verfassung und seine Krise 358-387 Fünftes Kapitel: Aufbauende und zerstörende Kräfte. Auflosung des Han-Reiches $\ldots \ldots \ldots \ldots \ldots \ldots \ldots \ldots \ldots .388-431$ 
